ISSN 1112-9867

http://www.jfas.info

\title{
UNCONSTRAINED MELTING AND SOLIDIFICATION INSIDE RECTANGULAR ENCLOSURE
}

\author{
A. A. Rabinataj Darzi ${ }^{1, *}$, H. Hassanzadeh Afrouzi ${ }^{2}$, M. Khaki ${ }^{1}$ and M. Abbasi ${ }^{1}$ \\ ${ }^{1}$ Department of Mechanical Engineering, Sari Branch, Islamic Azad University, Sari, Iran \\ ${ }^{2}$ Department of Mechanical Engineering, Babol University of Technology, Babol, Iran
}

Received: 13 June 2015 / Accepted: 30 August 2015 / Published online: 01 September 2015

\begin{abstract}
The present study concerns with the numerical study of unconstrained solidification and melting of phase change material (PCM) inside a two dimensional open rectangular cavity. The Cavity is filled by RT-27 as phase change material and air. Numerical study is carried out for different cavity aspect ratios. Result indicates that the conduction heat transfer is dominant at initial time of melting process where the layer of liquid PCM near hot surface is so thin. Solid PCM sinks to bottom of cavity due to higher density in respect to liquid PCM. Melting rate does not experience significant change by increasing cavity aspect ratio. The time of full solidification is much more than melting. It is due to the absence of natural convection with respect to melting process. By increasing the cavity aspect ratio, the solidification rates enhances significantly and its total time therefore reduces.
\end{abstract}

Keywords: Phase change material; melting; solidification; rectangular cavity.

Author Correspondence, e-mail: ar.darzy@gmail.com

doi: http://dx.doi.org/10.4314/jfas.v7i3.10

\section{INTRODUCTION}

In recent years, the Thermal Energy Storage (TES) technologies have been attracted the attention of researchers for its exceptional behavior. It can store energy for usage in a later 
period, which reduces the overall energy demand [1]. Phase change materials as one of most favorable TES method have been investigated in last three decades. These materials can be used for passive heat storage. They can absorb large amount of energy as latent heat at a constant phase transition temperature and release it later. PCMs have many useful properties including high storage density, chemical stability, low vapor pressure and small temperature drop during heat recovery process. These good properties allow it to be used in many industrial applications. The first study on PCM was presented by Barkmann and Wessling [2] for use in buildings, and later by other researchers [3-5]. There is a large number of experimental and numerical works on melting and solidification of PCM[6-10], and also its usage as thermal management in building [11-14], electronic devices [15-16] and solar energy [17-20].Most investigated geometries in melting and freezing process are sphere (spherical capsule), cylinder (shell and tube heat exchanger) and rectangular enclosure. Khodadadi and Zhang [21] studied the effect of buoyancy-driven convection on constrained melting of PCM in a spherical container numerically. They showed the rate of melting at the top region of sphere is faster than at the bottom region. Darzi et al. [22] studied numerically the melting of PCM between two cylinders in concentric and eccentric array. They found that natural convection plays important roles in melting. Jourabian et al. [23] performed a numerical analysis on melting of PCM inside an inclined cavity by using lattice Boltzmann method. They carried out the simulation at different Rayleigh numbers ranging from $10^{4}$ to $10^{6}$, different inclination angles ranging from -30 to 30 at the Stefan number of 10 . The results showed that Melting rate enhances by increasing Rayleigh number and the effect of natural convection becomes more dominantwhen the cavity is inclined counterclockwise, while, if it is inclined clockwise, the conduction heat transfer is the dominant mechanism. The main drawback of most phase change materials is related to low thermal conductivity especially in liquid state. Many researchers have been focused on enhancing the thermal conductivities of PCMs by introducing fins, metal foam and metal fibers in from of honeycomb, brush and wool [24]. Huang et al. [25] carried out an experimental and numerical work on melting of PCM enhanced by fin for cooling of photovoltaic devices. They found that by using fin can be improve the thermal performance but the use of a large number of fins decrease the natural 
convection within liquid PCM. Akhilesh et al. [26] performed a numerical study on fin-enhanced melting of PCM inside cavity heated from above. Their result reveals that melting rate increase by more fins while there is a critical value in the number of fins that does not improve the performance. Jourabian et al. [27] studied numerically the effect of fin on melting rate in a cavity based on enthalpy-porosity technique.They considered a cavity with a vertical hot wall while other walls to be adiabatic. They examined the vertical position of fin, relative thermal conductivity of fin to PCM and fin length on melting rate. They found that the best place for mounting fin is in the middle of hot wall.in addition their results indicates that it can be reached to complete melting in shorter time by using longer fin and higher thermal conductivity of fin.

The objective of present is numerical analysis of unconstrained melting and solidification of RT27 inside rectangular open cavity. Two side walls play as vertical fins for the cavity.Different aspect ratios are considered to examine their effects on melting and solidification rates. Result is provided as melt fraction plot versus time, instantaneous temperature and melts fraction contours.

\section{MATHEMATICAL MODEL}

\subsection{Problem statement}

The computational domain of the two dimensional model is shown in Fig.1. The thickness of cavity walls is $2 \mathrm{~mm}$. three different aspect ratiosare considered for cavity with identical volume. Their geometry specifications are given in table 1 .

The properties of the PCM based on a commercially available material, RT27 (Rubitherm $\mathrm{GmbH}$ ), is given in Table2.In addition, linear vitiation from solid properties to liquid properties is considered for mushy state andvariable density is defined in the liquid state as $\rho=\rho_{\text {liquid }}\left(\beta\left(T-T_{\text {liquid }}\right)+1\right)^{-1}$ for $30^{\circ} \mathrm{C}<\mathrm{T}<100{ }^{\circ} \mathrm{C}$. It is assumed that bothsolid and liquid phases are homogeneous and isotropic.In the initial state, the PCM fills $85 \%$ of theenclosed space. This is due to large difference between solid and liquid density that causes a significant increase in the PCM volume during the melting. ThePCM is exposed to airfrom above. A density-temperature relation is used for air: $\rho=1.2 \times 10^{-5} T^{2}-0.01134 T+$ 3.4978 . 


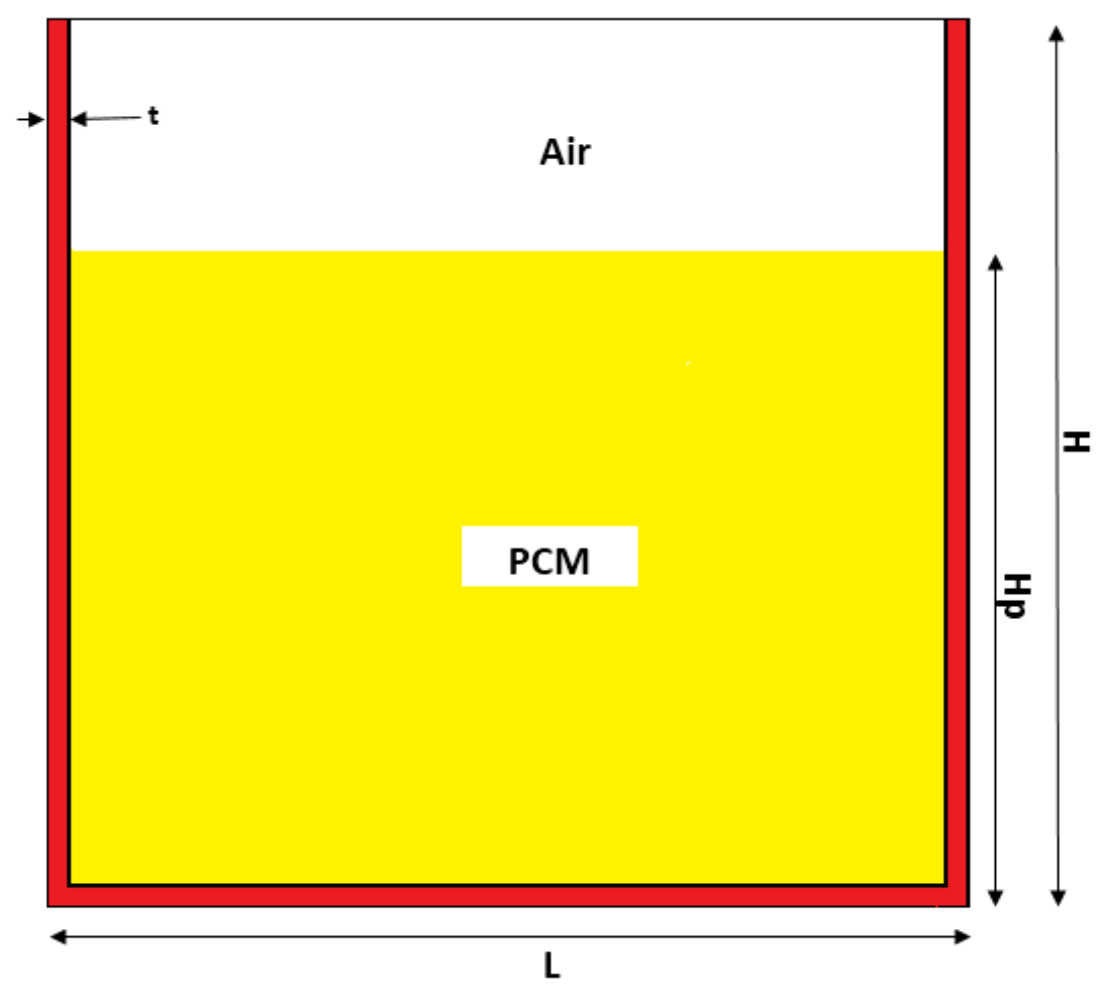

Fig.1. Schematic of computational domain

Table 1. Geometry specifications of enclosure

\begin{tabular}{ccccc}
\hline & $\mathbf{L}(\mathbf{m m})$ & $\mathbf{H}(\mathbf{m m})$ & $\mathbf{H p}(\mathbf{m m})$ & Aspect ratio $(\mathbf{H p} / \mathbf{L})$ \\
\hline Case1 & 42 & 42 & 31 & 0.74 \\
Case2 & 31.5 & 55 & 39 & 1.24 \\
Case3 & 22 & 80 & 70 & 3.18 \\
\hline
\end{tabular}

Table 2. Thermophysical properties of RT27

\begin{tabular}{ll}
\hline melting temperature & $28-30{ }^{\circ} \mathrm{C}$ \\
Density(solid-liquid) & $870-760 \quad \mathrm{~kg} / \mathrm{m}^{3}$ \\
Kinematics Viscosity & $3.42 \times 10^{-3} \quad \mathrm{~m}^{2} / \mathrm{s}$ \\
Specific Heat(solid-liquid) & $2400-1800 \quad \mathrm{~J} / \mathrm{kg} \mathrm{K}$ \\
Thermal Conductivity(solid-liquid) & $0.24-0.15 \quad \mathrm{~W} / \mathrm{m} \mathrm{K}$ \\
Latent Heat of Fusion & $179 \mathrm{~kJ} / \mathrm{kg}$ \\
Thermal Expansion Coefficient & $0.0005 \quad \mathrm{~K}^{-1}$ \\
\hline
\end{tabular}




\subsection{Governing equations}

In the numerical study, the flow is considered unsteady, laminar, incompressible and two-dimensional. Viscous dissipation term is considered negligible. The VOF model with pressure based solver and $1^{\text {st }}$-order implicit unsteady formulation used in FLUENT 6.3 software. The VOF model can model two or more immiscible fluid by solving a single set of momentum equations and tracking the volume fraction of each of the fluids throughout the domain. In each control volume, the volume fraction of all phases sum to unity. The field for all variables and properties are shared by phases and represent volume average values, as long as the volume fraction of each of the phases is known at each location. Thus the variables and properties in any given cell are either purely representative of one of the phases or representative of mixture of the phases, depending upon volume fraction value. In other word if the $\mathrm{q}^{\text {th }}$ fluid's volume fraction in the cell denoted as $\alpha_{\mathrm{q}}$ then the following three conditions are possible: $\alpha_{\mathrm{q}}=0$ the cell is empty of the $\mathrm{q}^{\text {th }}$ fluid, $\alpha_{\mathrm{q}}=1$ the cell is full of $\mathrm{q}^{\text {th }}$ fluid and $0<\alpha_{\mathrm{q}}<1$

the cell contain interface between $q^{\text {th }}$ and other fluid. Based on the local value of $\alpha_{q}$, the appropriate properties and variable will be assigned to each control volume within the domain.The continuity and Momentum equations used here for PCM-air system are:

$\frac{\partial \propto_{q}}{\partial t}+u_{i} \frac{\partial \propto_{q}}{\partial x_{i}}=0$

$\frac{\partial u_{i}}{\partial t}+\frac{\partial}{\partial x_{j}}\left(\rho u_{j} u_{i}\right)=-\frac{\partial p}{\partial x_{i}}+\mu \frac{\partial^{2} u_{i}}{\partial x_{j} \partial x_{i}}+\rho g_{i}+S_{i}$

An enthalpy-porosity technique [28] is used in FLUENT for modeling the solidification/melting process. In this technique, the melt interface is not tracked explicitly. Instead, a quantity called the liquid fraction, which indicates the fraction of the cell volume that is in liquid form, is associated with each cell in the domain. The liquid fraction is computed at each iteration, based on an enthalpy balance. The mushy zone is a region in which the liquid fraction lies between 0 and 1 . The mushy zone is modeled as a "pseudo" porous medium in which the porosity decreases from 1 to 0 as the material solidifies. When the material has fully solidified in a cell, the porosity becomes zero and hence the velocities also drop to zero.For solidification/melting problems, the energy equation is written as: 


$$
\frac{\partial}{\partial t}(\rho h)+\frac{\partial}{\partial t}\left(\rho u_{i} h\right)+\frac{\partial}{\partial t}(\rho \Delta H)=\frac{\partial}{\partial x_{i}}(k \nabla T)
$$

In these relations, $u_{i}$ is the fluid velocity, $\rho$ is the PCM's density, $\mu$ is the dynamics viscosity of $\mathrm{PCM}, P$ is the pressure, $\mathrm{g}$ is the gravitational acceleration, $k$ is the effective thermal conductivity and $h$ is sensible enthalpy that is defined as following:

$h=h_{r e f}+\int_{T_{r e f}}^{T} C_{p} d T$

The enthalpy, $\mathrm{H}$, is therefore:

$H=h+\Delta H$

Where $\Delta H$ being the latent heat content may vary between zero (solid) and L (liquid), the latent heat of the PCM. Therefore liquid fraction, $\beta$, can be defined as following:

$\lambda=\left\{\begin{array}{lrl}\frac{\Delta H}{L}=0 & T<T_{s} \\ \frac{\Delta H}{L}=0 & T>T_{l} \\ \frac{\Delta H}{L}=\frac{T-T_{s}}{T_{l}-T_{s}} T_{s}<T<T_{l}\end{array}\right.$

In equation 2, $S_{i}$ is the Darcy's law damping terms (as source term) that are added to the momentum equation due to phase change effect on convection. It is defined as:

$$
S_{i}=\frac{C(1-\lambda)^{2}}{\lambda^{3}} u_{i}
$$

That coefficient $\mathrm{C}$ is a mushy zone constant that is fixed to $10^{5} \mathrm{~kg} / \mathrm{m}^{3} \mathrm{~s}$ and $10^{6} \mathrm{~kg} / \mathrm{m}^{3} \mathrm{sfor}$ melting and solidification, respectively, in the present study [29, 30].

\subsection{Numerical procedure and validation}

The momentum and energy equations are solved by the power law scheme. The PISO method is used for pressure-velocity coupling. Also the PRESTO scheme is adopted for the pressure correction equation. The under-relaxation factors of $0.7,0.3,1$ and 0.9 are used for the velocity components, pressure correction, thermal energy and liquid fraction, respectively. In order to ensure of solution independency from adopted grid density based on comparison of melting fraction, different grid densities are tested (fig.2). 


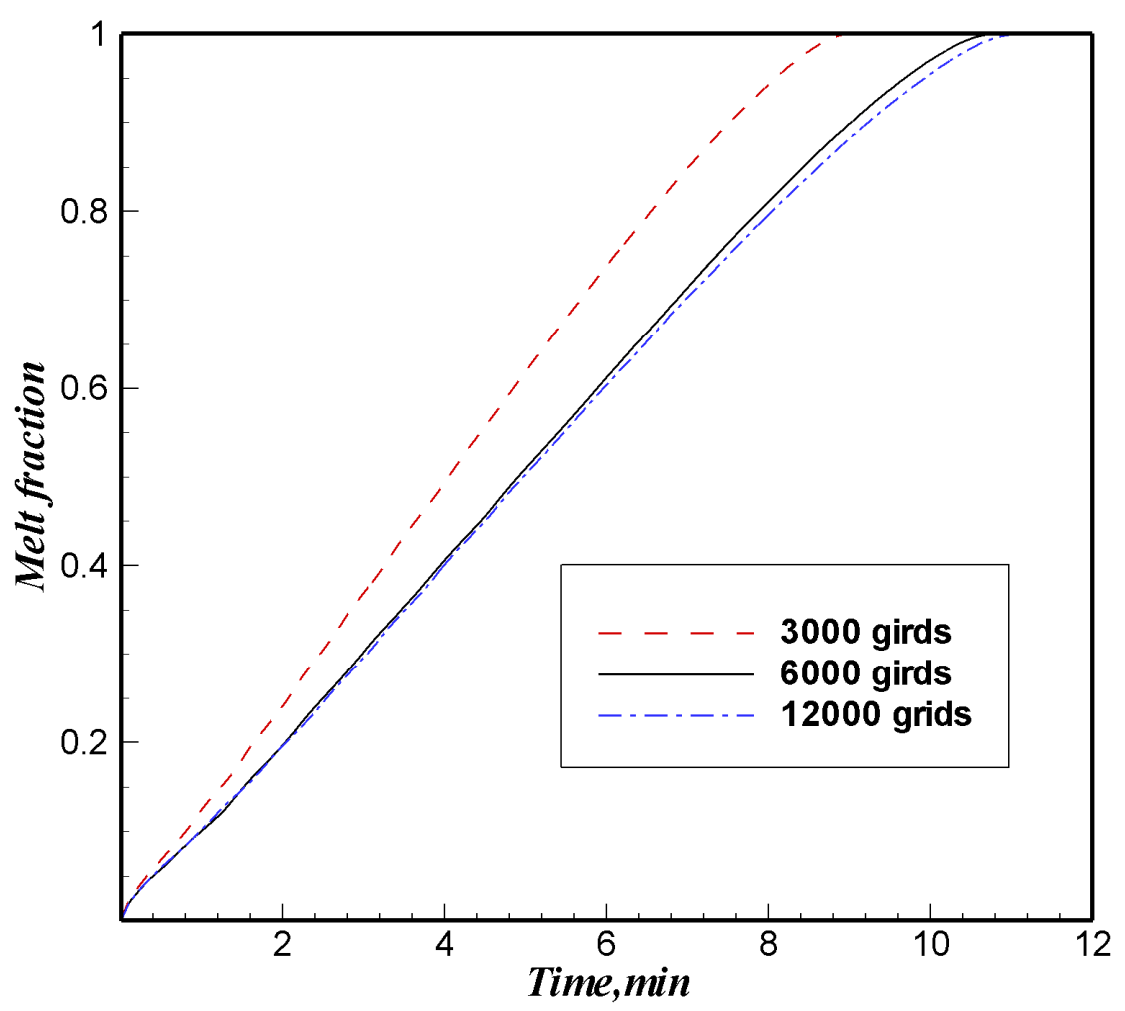

Fig.2. Sensitivity of numerical solution to grid size

An arrangement of 6000 grids is found sufficient for present study. The time step is set to 0.001 seconds in initial stage and then is gradually increased to 0.01 . The number of iterations for every time step is considered 40 to satisfy the convergence criteria $\left(10^{-6}\right)$. In order to validate the present work, initial run is performed inside a sphere with diameter of $40 \mathrm{~mm}$ and temperature difference of $10^{\circ} \mathrm{C}(\mathrm{Ste}=0.1)$. Fig. 3 shows the comparison of melt fraction versus time. It can be observed that the present study shows a good agreement with those of Assis et al. [29]. 


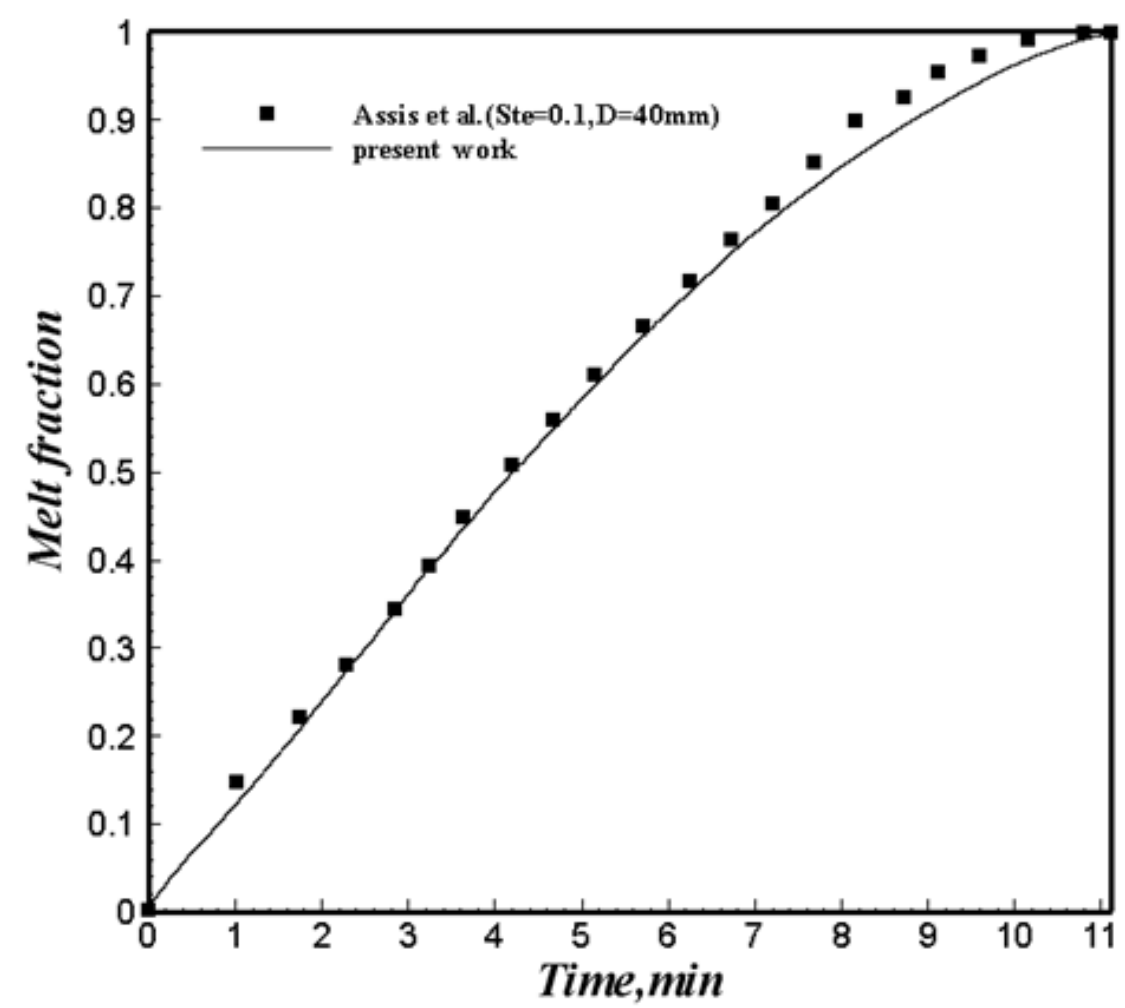

Fig.3. Comparison of melt fraction inside a sphere with diameter of $40 \mathrm{~mm}$ between present study and Assis et al. work

\section{RESULTS AND DISCUSSION}

Contours of melt fraction and temperature of PCM during melting process are shown in fig. 4 . At initial time, a thin layer of PCM is melted near the walls at bottom and sides where solid PCM contacts with hot surfaces. The bottom wall is hot and side walls play as fins for it. Heat conduction through side walls increases the temperatures of them. Solid PCM near the walls absorbs heat and the temperature increases up. It continues up to melting point. In this stage the absorbed heat is consumed for phase change. After that the PCM is melted and the temperature of liquid PCM increases. Pure heat conduction is the dominant mechanism in initial time when the thickness of liquid PCM is so thin. The heat transfer from hot bottom to PCM is greater than other places because of direct contact between hot surface and PCM. 


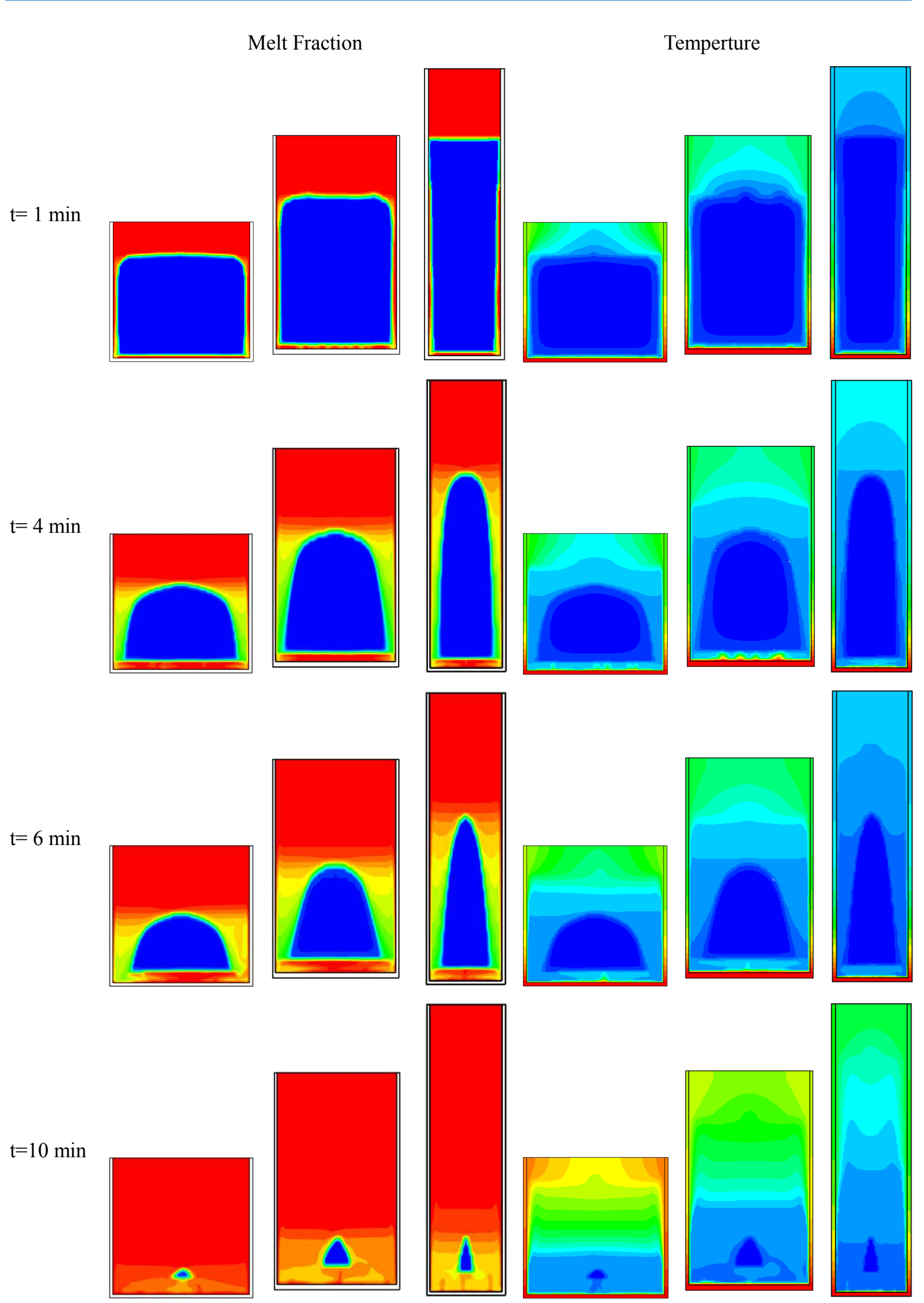

Fig.4. Natural convection within melted $\mathrm{PCM}$ at $\mathrm{t}=7 \mathrm{~min}$ 
Thus, the melting rate in the bottom of cavity is higher than others at initial time. By passing time, the thickness of liquid PCM becomes bigger and the buoyancy force is empowered. The hot melted liquid PCM near the hot surfaces rise up through the side walls to top region of cavity and the cold PCM near solid PCM sink down (fig.5). The heat convection becomes more significant when the liquid PCM gets thicker. The difference between solid and liquid density of PCM causes solid PCM sink toward the bottom of the cavity and push up hot liquid PCM. It intensifies the convection force and accelerate the melting rate. However, it can be noticed that the thermal conductivity of liquid PCM is lower than Solid PCM and therefore, the heat conduction in liquid PCM is lower than in solid PCM. Thus, by increasing the thickness of liquid layer between hot surfaces and solid PCM, the conduction heat transfer is reduced while natural convection is enhanced. At top region of PCM zone, the melting is accelerated because of severe natural convection. It causes to forming the dome-shape solid PCM. Variation of melt fraction versus time for different aspect ratios is illustrated in fig.6. Slope of these plots represents the melting rate. Curves have sharp slope at initial time where pure conduction is the dominant mechanism and then decreases where a thick layer of liquid PCM is formed between solid PCM and hot surfaces. It can be seen that increase of aspect ratio from 0.74 to 1.24 increases slightly the full melting time. While more increase of aspect ratio from 1.24 to 3.18 has not significant effect on melting rate.

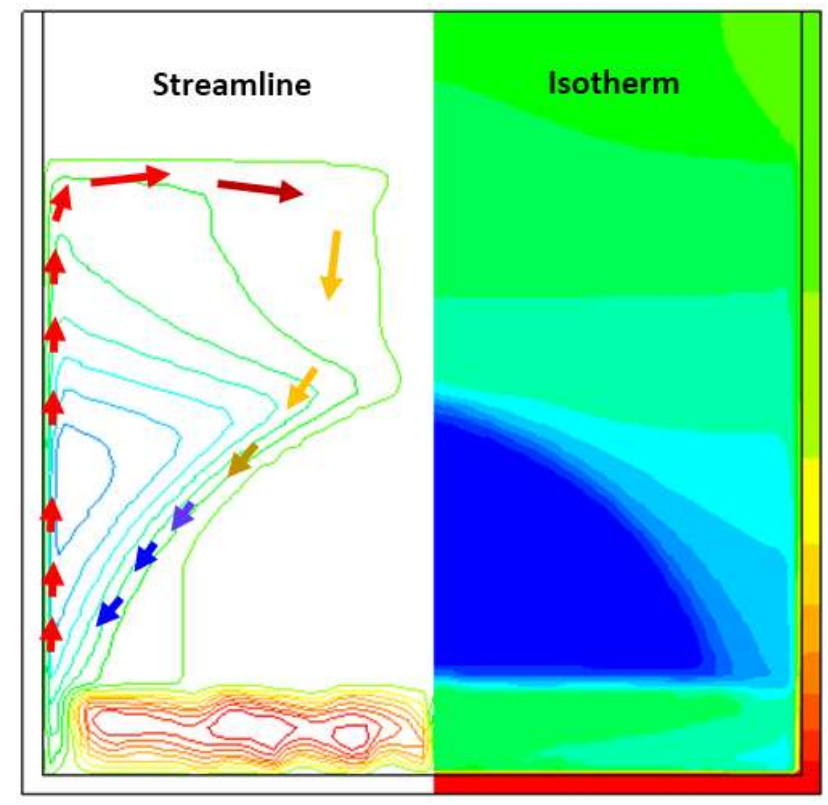

Fig.5. Detailed melt fraction and temperature contours throughout melting process for different aspect ratios 


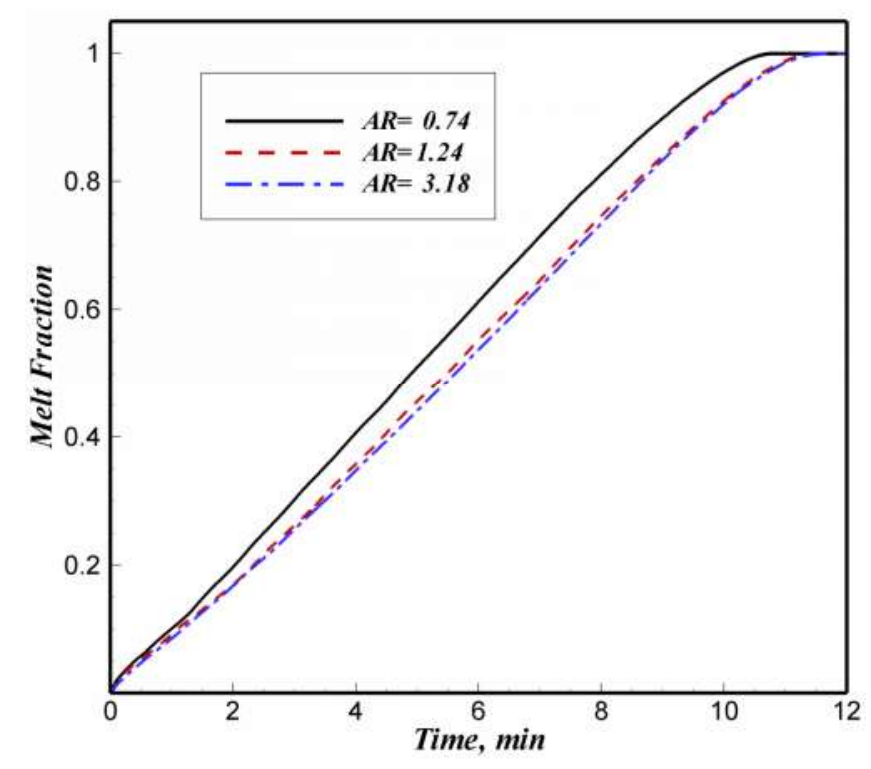

Fig.6. Evaluations of melt fraction versus time

Colorized melt fraction contours for different aspect ratios during solidification process are depicted in fig.7. The temperature of bottom wall sets at $280 \mathrm{~K}$ (12K below melting point). By transferring heat from PCM to cold walls decreases the PCM temperature to solidus temperature. By more transferring heat, phase changes and then the temperature of PCM maintains at solidus temperature. Solid PCM is formed near cold bottom wall and side walls. By passing time, the thickness of solid PCM becomes bigger especially near bottom wall. Solid PCM is heavier than liquid PCM and therefore it is accomplished on bottom wall. Fig. 8 shows the evaluations of melt fraction during solidification process at different aspect ratios. It can be seen in initial time, the solidification rate is great and the plots have overlap until 5minutes where heat conduction is the dominant mechanism of heat transfer between liquid PCM and cold surfaces. After 5 minutes, the plots diverge from each other. The solidification rate increases at higher aspect ratio where the cold vertical surfaces are taller and horizontal cold surface is smaller. As mentioned before, conductionisthe dominant mechanism of heat transfer in solidification process. To this reason, the full solidification time is longer than full melting time. By progressing time, the more amount of PCM becomes solid and therefore the solid layer near cold surfaces gets thicker. Although the thermal conductivity of solid PCM is greater than liquid PCMbut solid layer plays as thermal resistance for heat conduction from cold surface to warm liquid PCM. 
$\mathrm{t}=1 \mathrm{~min}$
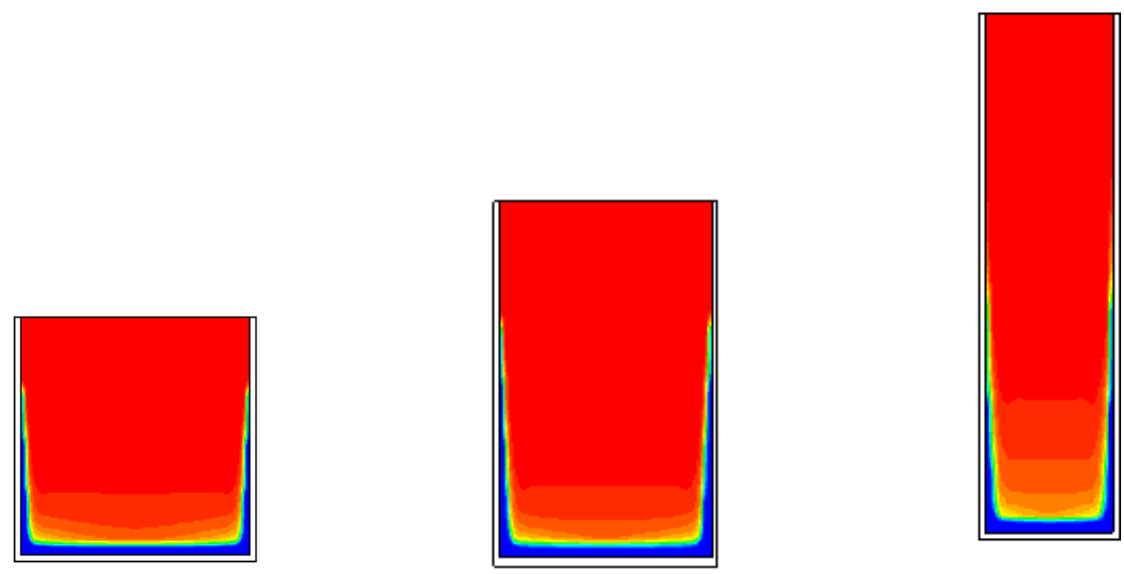

$\mathrm{t}=4 \min$
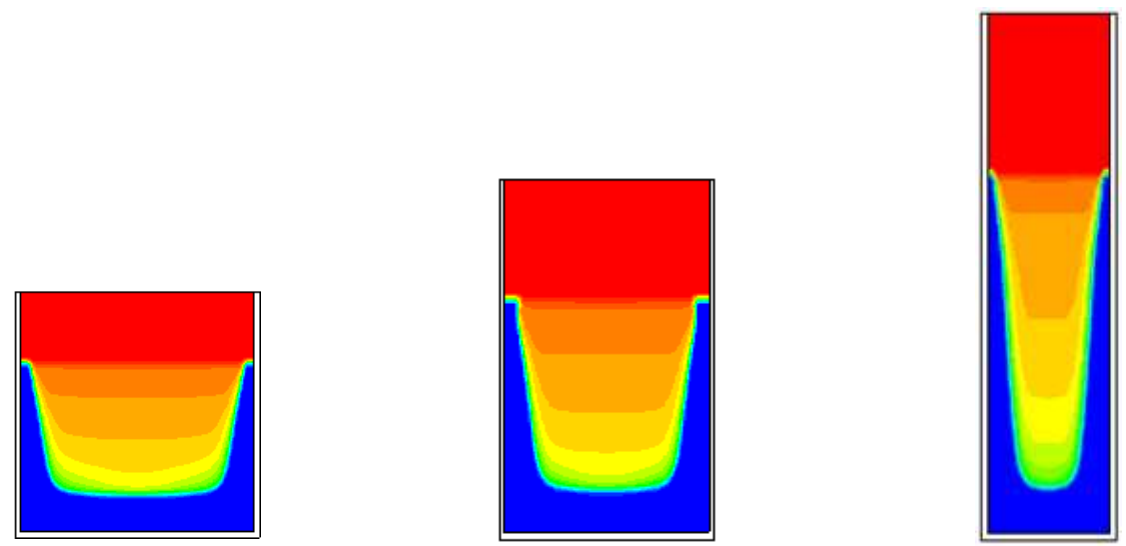

$\mathrm{t}=15 \min$
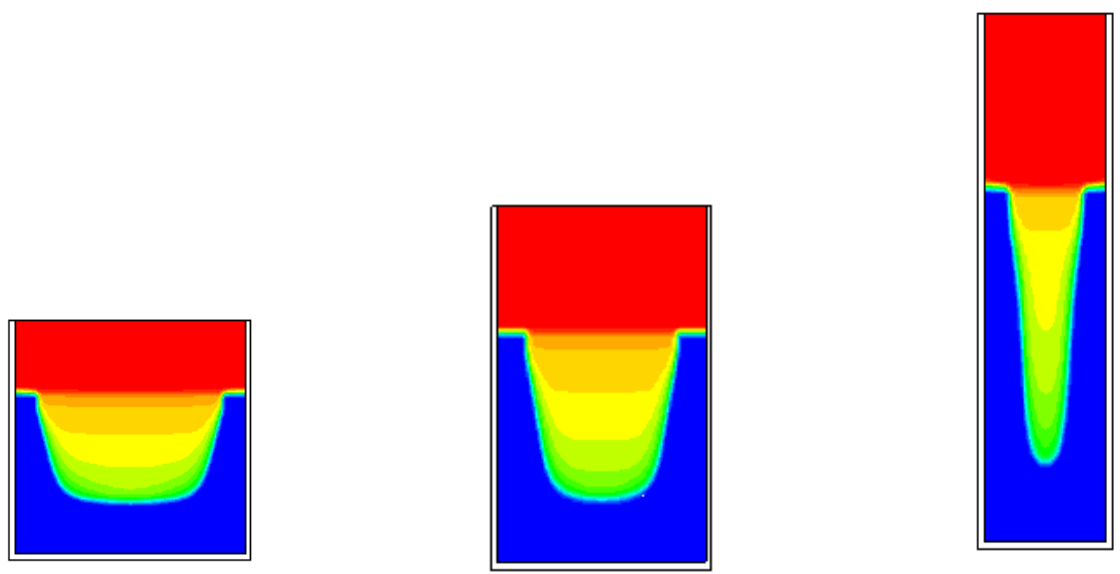

$\mathrm{t}=30 \min$
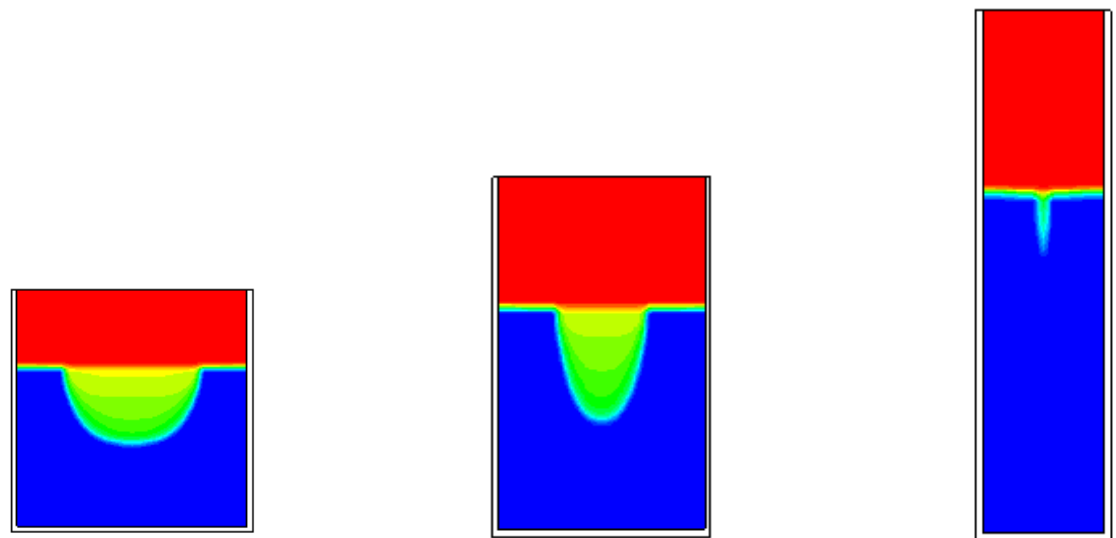

Fig.7. Melt fraction contours during solidification phenomenon 


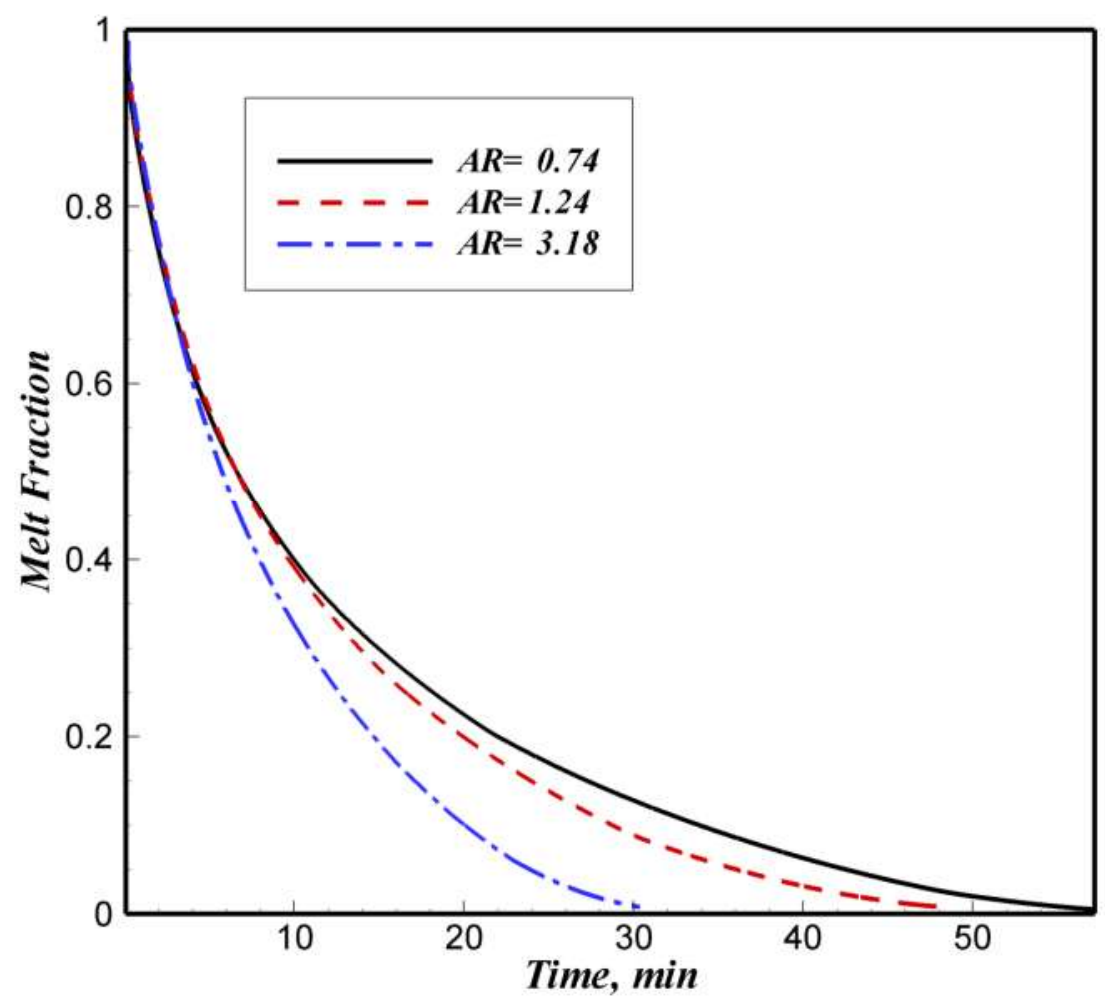

Fig.8. Variation of Melt fraction versus time for various aspect ratios

Thus, heat conduction decreases by increasing thickness of solid PCM. Solidification rate reduces gradually during process especially near end of process where the solid PCM covers the whole of cavity expect a small region at the top of the PCM zone. It can be seen that the full solidification of PCM occurs at 60, 48 and 30 minutes for Aspect ratios of 0.74, 1.24 and 3.18, respectively. It depicts that solidification enhances severely by increasing aspect ratio against melting process. Bigger vertical cold walls enhance the conduction and therefore the solidification rate becomes greater.

\section{CONCLUSION}

In this paper, the unconstrained melting and solidification process was investigated inside open cavity with different aspect ratios. VOF multiphase model was implemented to simulate the flow and heat transfer of PCM and air.Results reveal thatfull melting occurs earlier than full solidification. In the initial time the melting and solidification have high rate where conduction heat transfer is dominant mechanism. By passing time, the melting and solidification rate reduce because of thermal resistance induced by layer of melted PCM (in 
melting) or solid PCM (in solidification). Increasing the aspect ratio of cavity has not significant effects on melting while it enhances the solidification rate noticeably.

\section{Nomenclature}

C $\quad\left[\mathrm{kg} / \mathrm{m}^{3} \mathrm{~s}\right] \quad$ Mushy zone constant

$C_{P} \quad[\mathrm{~J} / \mathrm{kg} \mathrm{K}] \quad$ Specific heat

$d_{s} \quad[\mathrm{~m}] \quad$ Diameter of nano-particle

$g \quad\left[\mathrm{~m}^{2} \mathrm{~s}^{-1}\right] \quad$ Gravitational acceleration

$h \quad[\mathrm{~J} / \mathrm{kg}] \quad$ Sensible enthalpy

$H \quad[\mathrm{~J} / \mathrm{kg}] \quad$ Enthalpy

$k \quad[\mathrm{~W} / \mathrm{mK}] \quad$ Thermal conductivity

$L \quad[\mathrm{~J} / \mathrm{kg}] \quad$ Latent heat fusion

$T \quad[\mathrm{~K}] \quad$ Temperature

$u \quad[\mathrm{~m} / \mathrm{s}] \quad$ Velocity

\section{Greece symbols}

$\begin{array}{ccl}\mu & {[\mathrm{Kg} / \mathrm{ms}]} & \text { Dynamic viscosity of the fluid } \\ \rho & {\left[\mathrm{kg} / \mathrm{m}^{3}\right]} & \text { Density } \\ v & {\left[\mathrm{~m} / \mathrm{s}^{2}\right]} & \text { Kinematics viscosity } \\ \beta & {[1 / \mathrm{K}]} & \text { Thermal expansion coefficient } \\ \lambda & - & \text { Liquid fraction } \\ \propto & - & \text { volume fraction of fluid }\end{array}$

\section{ACKNOWLEDGMENT}

The present study is supported by the Sari branch, Islamic Azad University, Iran

\section{REFERENCES}

[1] Mehling H., Cabeza L, Phase change materials and their basic properties. In: Paksoy HÖ, editor, Thermal energy storage for sustainable energyconsumption. Netherlands: Springer; 2007, pp. 257-77.

[2] Barkmann H.G and Wessling F.C. Use of buildings structural components for thermal storage, Proceedings of the Workshop on Solar Energy Storage Subsystems for the Heating and Cooling of Buildings, Charlottesville (Virginia, USA), 1975.

[3] Hawes D.W., Feldman D and Banu D, Energ Buildings, 1993, 20, pp. 77-86. 
[4] Morikama Y., Suzuki H., Okagawa F and Kanki K. Proceedings of the International Symposium on Thermal Application of Solar Energy, Hakone (Kanagawa, Japan), 1985.

[5] Sokolov M and Keizman Y, Sol. Energ, 1991, 47, pp. 339-346.

[6] Hosseinizadeh S.F., Rabienataj Darzi A.A., Tan F.L, Int. J. Therm Sci, 51, pp. 77-83.

[7] Hosseinizadeh S.F., Rabienataj Darzi A.A., Tan F.L, Khodadadi J.M., Int. J. Therm. Sci, 63, pp. 55-64.

[8] Jourabian M., Farhadi M., Rabienataj Darzi AA, Appl. Math. Model, 37(20), pp. 8813-8825.

[9] Jourabian M., Farhadi M., Rabienataj Darzi A.A., Heat. Mass. Trans, 49(4), pp. 555-565.

[10] Rabienataj Darzi A.A., M Farhadi, M Jourabian, Y Vazifeshenas, INT J Numer Method H, 24 (1), pp. 221-236

[11] Kong X., Lu S., Li Y., Huang J., Liu S., Energ. Build, 2014, 80, pp. 404-415.

[12] Persson J., Westermark M, Energ. Build, 2012, 54, pp. 490-495.

[13] Soares N., Costa J.J., Gaspar A.R., Santos P., Review of passive PCM latent heat thermal energy storage systems towards buildings' energy efficiency, Energ. Build, 2013, 59, pp. 82-103.

[14] Chaiyat N., Kiatsiriroat T., Case Stud. Therm. Eng, 2014, 4, pp. 175-186.

[15] Weng Y.C., Cho H.P., Chang C.C., Chen S.L, Appl.Energ, 2011, 88(5), pp. 1825-1833.

[16] Alshaer W.G., Nada S.A., Rady M.A., Del Barrio E.P., Sommier A, Int. J. Therm. Sci, 2015, 89, pp. 79-86.

[17] Shalaby S.M., Bek M.A., El-Sebaii A.A, Renewable and Sustainable Energy Reviews, 2014, 33, pp. 110-116,

[18] Kousksou T., Bruel P., Cherreau G., Leoussoff V., El Rhafiki T., Sol. Energ, 2011, 85(9), pp. $2033-2040$

[19] Mahfuz M.H., Anisur M.R., Kibria M.A., Saidur R., Metselaar I.H.S.C, Int. Comm. Heat. Mass. Trans, 2014, 57, pp. 132-139.

[20] Hussain H. Lin C, Sol. Energ, 2014, 109, pp. 82-92.

[21] Khodadadi, J.M. and Zhang, Y, Int. J. Heat Mass Transfer, 2001, 44, pp. 1605-1618.

[22] Rabienataj Darzi A.A., Farhadi M., Sedighi K, Appl. Math. Model, 36(9), 2012, pp. 
$4080-4086$.

[23] Jourabian M., Farhadi M., Rabienataj Darzi A.A, Scientia Iranica, 2012, 19(4), pp. 1066-1073.

[24] Fan L., Khodadadi JM., Renew Sustain Energ. Rev, 2011;15, pp.24-46.

[25] Huang M.J., Eames P.C., Norton B, Int. J. Heat Mass Transfer, 2004, 47(12-13), pp. $2715-2733$.

[26] Akhilesh R., Narasimhan A., Balaji C, Int. J. Heat Mass Transfer, 2005, 48(13), pp. $2759-2770$.

[27] Jourabian M., Farhadi M., Sedighi K., Rabienataj Darzi A.A. and Vazifeshenas Y, Int. J. Numer. Meth. Fluids, 2012, 70(3), pp. 313-325.

[28] Brent A D., Voller V.R., and Reid K.J, Num. Heat Trans, 1988, 13, pp. 297-318.

[29] Assis E., Katsman L., Ziskind G and Letan, R, Int. J. Heat Mass Trans, 2007, 50, pp. $1790-1804$.

[30] Assis E., Ziskind G and Letan R, J. Heat Transfer, 2009, 31(1), pp. 24502-24507.

\section{How to cite this article:}

Rabinataj Darzi A A, Hassanzadeh Afrouzi H, Khaki M And Abbasi M. Unconstrained melting and solidification inside rectangular enclosure. J. Fundam. Appl. Sci., 2015, 7(3), 436-451. 